\title{
Ege Üniversitesi hastanesi veri tabanındaki pankreas kanserlerinin epidemiyolojik ve genel sağkalım özellikleri
}

\section{Epidemiologic and survival characteristics of pancreatic cancers in Ege University} hospital database

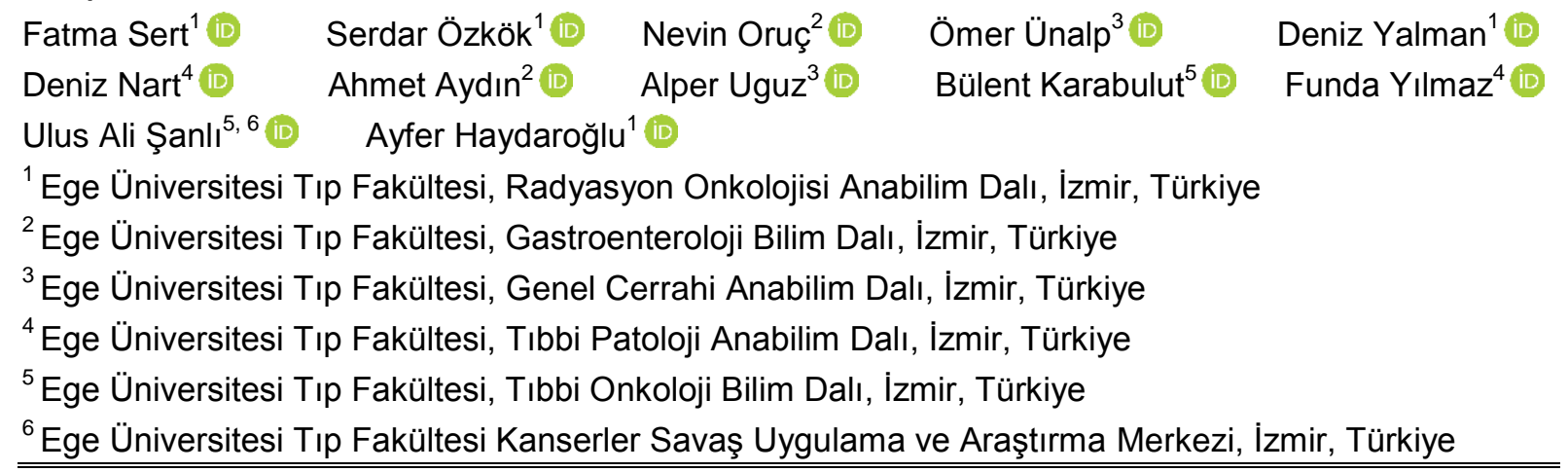

\section{Öz}

Amaç: Pankreas kanserlerinin epidemiyolojisi ve genel sağkalım (GSK) özelliklerinin araştırılmasıdır.

Gereç ve Yöntem: Ege Üniversitesi Kanserle Savaş Uygulama ve Araştırma Merkezine (EÜKAM) 1992-2017 yıllarında kayıtıı Ege Üniversitesi Tıp Fakültesi (EÜTF) kanser verileri retrospektif olarak taranmıştır. CANREG özel bilgisayar programına kayıtlı veriler, WHO ve Surveillance, Epidemiology, and End Results (SEER) sistemlerinde gruplanarak analizler yapılmıştır. İstatistiksel analizlerde Kikare, General Linear Model (GLM), Kaplan-Meier sağ kalım analizleri kullanıımıştır.

Bulgular: Toplam 117.139 kanser olgusunun 2.507'si pankreas kanseridir. Olgularımızın 1.493'ü $(\% 59,5)$ erkek, 1.014'ü $(\% 40,5)$ kadın olup pankreas kanseri iki cinsiyette benzer oranlarda izlenmektedir. Pankreas başı, en sık yerleşim yeridir. Genellikle ileri evrede tanı konulan kuyruk yerleşimli tümörler, erkeklerde daha sıktır (\%11,5 vs. \%6,2; $p=0,047)$. Erkeklerde en sık 6069 yaş arasında, kadınlarda ise 70 yaş üzerinde izlenmektedir. Ekzokrin tümörler, endokrin tümörlerden anlamlı oranda fazla karşılaşılmaktadır (\%95 vs. \%5; $p=0,002)$. 1992 yılından 2014 yılı sonuna kadar kaydedilen pankreas kanseri olgularında doğrusal bir artış mevcuttur ve yıllara göre olan bu artış anlamlıdır (GLM: $F=10,91, p<0,001$ ). Artış cinsiyetler arasında farklılık göstermektedir. Erkeklerde daha yüksek ve doğrusal artış olduğu saptanmıştır (GLM: $F=4,988, p=0,026)$. Hastalık prognozu oldukça kötü olup 2-, 5- ve 10-yıllık GSK oranları sırasıyla \%15,9, \%8,3 ve \%6,0; ortanca GSK 7 aydır. Beş yıllık GSK erkeklerde \%11,3 iken; kadınlarda \%15,4 olup fark anlamlı bulunmuştur ( $p<0,001)$.

Sonuç: EÜTF'de EÜKAM tarafından 1992-2017 arasında, 117.139 kanser kaydı gerçekleştirilmiş, bunların 2507'si pankreas kanseridir. Pankreas kanserinde yıllara göre doğrusal artış vardır ve uzak metastatik evrede tanı konulmaktadır. En sık görülme yaş grubu olan 60-69 yaş grubu için 5 yıllık GSK $\% 1,4$ olarak bulunmuştur. Kadınlarda GSK erkeklere göre daha iyidir.

Anahtar Sözcükler: Pankreas kanseri, epidemiyoloji, mortalite, genel sağkalım.

Sorumlu yazar: Fatma Sert

Ege Üniversitesi Tıp Fakültesi, Radyasyon Onkolojisi

Anabilim Dalı, İzmir, Türkiye

E-posta: gracilis81@gmail.com 


\begin{abstract}
Aim: To determine epidemiological and overall survival (OS) characteristics of pancreatic cancer patients.

Materials and Methods: Data of Ege University Cancer Control and Research Center between 19922017 were screened retrospectively. Data recorded in CANREG program were grouped and analyzed in WHO and Surveillance, Epidemiology, and End Results (SEER) systems. Chi-square test, General Linear Model (GLM) and Kaplan-Meier survival analysis were used for statistical analysis.

Results: Number of pancreatic cancer cases was 2,507 among 117,139 cancer cases. 1,493 (59.5\%) of our cases were male and 1,014 (40.5\%) were female. Pancreatic head was the most common location. Tail located tumors were more common in males $(11.5 \% \mathrm{vs} .6 .2 \% ; p=0.047)$. It was most common in males between the ages of 60 and 69, in females over the age of 70 . Exocrine tumors were significantly higher than endocrine tumors ( $95 \%$ vs. $5 \% ; p=0.002)$. There was a linear increase in pancreatic cancer cases recorded from 1992 to the end of 2014, and this increase over the years was significant (GLM: $F=10.91, p<0.001$ ). A higher and linear increase was found in men (GLM: $F=4.988$, $p=0.026$ ). Disease prognosis was poor and 2, 5 and 10 year OS rates were $15.9 \%, 8.3 \%$ and $6.0 \%$, respectively; median OS was 7 monhts. While 5 -year OS was $11.3 \%$ in men; $15.4 \%$ of women and it was found significant $(p<0.001)$.
\end{abstract}

Conclusion: There was a linear increase in pancreatic cancer over the years and the diagnosis was done in distant metastatic stage. The 5-year OS was $1.4 \%$ for the $60-69$ years age group. OS was better in women than men.

Keywords: Pancreatic cancer, epidemiology, mortality, overall survival.

\section{Giriş}

Pankreas kanseri, nadir görülen bir kanser tipi olmakla beraber ileri evrede tanı alması nedeni ile genellikle kötü sağkalım sonuçlarına sahiptir. Gelişmiş ülkelerde genel kanser ölümlerinin yedinci ve Amerika'da ise dördüncü en sık gelen nedenidir (1). Ülkemizde ise nadir görülen kanser tipleri arasında yer almaktadır (2). GLOBOCAN 2018 tahminlerine göre, 2018 yılında 458.918 yeni olgu sayısı ve 432.242 ölüm ile (tüm kanser nedenli ölümlerin $\% 4,5 ' i)$ on birinci en sık karşılaşılan kanser tipi olarak verilmektedir (1).

Her ne kadar etiyolojisi net olarak tanımlanamamış olsa da bazı risk faktörleri belirlenmiştir. Bu risk faktörleri, ileri yaş (>60 yaş), erkek cinsiyet, sigara, alkol kullanımı, aile anamnezi olması, geçirilmiş mide operasyonu öyküsü ve diyabet tanısına sahip olmak şeklinde sayılabilir (3). Özellikle 40 yaş altında nadir izlenirken; 50 yaş üzerinde insidansı artmaya başlamaktadır.

Pankreas kanseri, semptomlarının non-spesifik olması nedeni ile sıklıkla lokal ileri veya metastatik evrede tanı almaktadır. Bu nedenle sağkalım verileri değerlendirildiğinde, mortalitesi yüksek bir kanser tipidir. Yalnızca \%10-20 olgu erken evrede tanı alabilmektedir (3).

$\mathrm{Bu}$ makalenin amacı; nadir karşılaşılan ancak buna karşın sağkalım oranları düşük olan pankreas kanserini için Ege Üniversitesi Hastanesinde (EÜH), 1992-2017 yılları arasında tedavisi yapılan 2.507 olgunun epidemiyolojik ve genel sağ kalım (GSK) özelliklerinin ortaya konmasıdır. Çalışmamız Ege Üniversitesi Tıbbi Araştırmalar Etik Kurulu tarafından onaylanmış ve multidisipliner hazırlanmıştır.

\section{Gereç ve Yöntem}

Ege Üniversitesi Kanserle Savaş Araştırma ve Uygulama Merkezinin (EÜKAM) özel eğitimli ve sertifikalı kanser kayıt elemanları tarafından 1992-2017 yılları arasında 25 yıllık dönemde EÜH'de 117.139 kanser kaydı gerçekleştirilmiş olup; bunun 19.542'si gastrointestinal sistem kanseridir. Gastrointestinal sistem kanserlerinin 2.507'si $(\% 12,8)$ pankreas kanseri tanısı ile tedavi edilmiştir (Tablo-1).

Sınıflandırmalarda ve sağ kalım analizlerinde SEER verileri göz önüne alınmıştır. CANREG 4 programı ile kaydedilen veriler SPSS programına aktarılmış, istatistik analizde Ki-kare testi ve doğrusal modellemeler yapılmış, $p<0,05$ değeri anlamlı kabul edilmiştir. Olgular, gastroenteroloji kliniğinde tanı alan ve hastanemizde ameliyat olan veya dışarıda tanı alıp radyoterapi ve kemoterapi gibi tedavilerini hastanemizde alan pankreas kanserli hastalardır. 
Tablo-1. Gastrointestinal Sistem tümörlerinin ve pankreas kanserlerinin cinsiyete göre dağılımı.

\begin{tabular}{lllllll}
\hline Yerleşim & Erkek & \multicolumn{2}{c}{ Kadın } & \multicolumn{2}{c}{ Toplam } \\
& $\mathbf{n}$ & $\%$ & $\mathbf{n}$ & $\%$ & $\mathbf{n}$ & $\%$ \\
\hline Özofagus & 573 & 4,8 & 436 & 5,7 & 1.009 & 5,2 \\
Mide & 2.692 & 22,6 & 1.520 & 20 & 4.212 & 21,6 \\
İnce Barsak & 178 & 1,5 & 109 & 1,4 & 287 & 1,5 \\
Kolorektal & 4.347 & 36,5 & 2.938 & 38,6 & 7.285 & 37,3 \\
Anal Kanal ve Anüs & 54 & 0,5 & 72 & 0,9 & 126 & 0,6 \\
Karaciğer ve İntrahepatik Safra Kanalları & 1.627 & 13,6 & 645 & 8,5 & 2.272 & 11,6 \\
Safra kesesi ve Ekstrahepatik Safra Kanalları & 808 & 6,8 & 761 & 10 & 1.569 & 8 \\
Pankreas & 1.493 & $\mathbf{1 2 , 5}$ & $\mathbf{1 . 0 1 4}$ & $\mathbf{1 3 , 3}$ & $\mathbf{2 . 5 0 7}$ & $\mathbf{1 2 , 8}$ \\
Appendiks ve Diğer GIS & 151 & 1,3 & 124 & 1,6 & 275 & 1,4 \\
& $\mathbf{1 1 . 9 2 3}$ & $\mathbf{1 0 0}$ & $\mathbf{7 . 6 1 9}$ & $\mathbf{1 0 0}$ & $\mathbf{1 9 . 5 4 2}$ & $\mathbf{1 0 0}$ \\
\hline
\end{tabular}

Tablo-2. ICD-O3'e sınıflamasına göre pankreas kanserlerinin yerleşim şekillerinin cinsiyet ile ilişkisinin gösterilmesi.

\begin{tabular}{lllllll}
\hline Yerleşim & Erkek & \multicolumn{2}{c}{ Kadın } & \multicolumn{3}{c}{ Toplam } \\
& $\mathbf{n}$ & $\%$ & $\mathbf{n}$ & $\%$ & $\mathbf{n}$ & $\%$ \\
\hline C25.0 Pankreas Başı & 766 & 51,3 & 556 & 54,8 & $\mathbf{1 . 3 2 2}$ & 52,7 \\
C25.1 Pankreas Gövdesi & 156 & 10,4 & 116 & 11,4 & 272 & 10,8 \\
C25.2 Pankreas Kuyruğu & 136 & 9,1 & 60 & 5,9 & 196 & 7,8 \\
C25.3 Pankreas Kanalı & 7 & 0,5 & 1 & 0,1 & 8 & 0,3 \\
C25.7 Pankreas diğer & 2 & 0,1 & 0 & 0,0 & 2 & 0,1 \\
C25.8 Pankreasta aşan lezyon & 105 & 7,0 & 69 & 6,8 & 174 & 6,9 \\
C25.9 Pankreas, BBT & 321 & 21,5 & 212 & 20,9 & 533 & 21,3 \\
Toplam & 1.493 & 100,0 & 1.014 & 100,0 & 2.507 \\
Ki Kare:12,630; p=0,04 & & & & & & 100,0 \\
\hline
\end{tabular}

\section{Bulgular}

EÜKAM tarafından, 1992-2017 arası 25 yıl içinde EÜH'de 117.139 kanser verisi toplanmıştır. Toplanan bu verilerin içinde 2.507'si pankreas kanseridir (Tablo-1). Olgularımızın 1.493'ü $(\% 59,5)$ erkek, 1.014'ü $(\% 40,5)$ kadın olup istatistiksel anlamlı farklılık gösterilememiş olsa da pankreas kanseri olgu sayısı erkek cinsiyette daha fazla izlenmektedir.

Pankreas başı olguların \%52,7'sinde en sık lokalizasyondur. Olgularımızın pankreastaki yerleşimine göre dağılımları tablo 2'de ayrıntılı olarak gösterilmiştir.

Pankreas tümör yerleşimleri cinsiyetlere göre incelendiğinde, erkeklerde pankreas başı tümörlerinin $\quad \% 51,5, \quad$ kadınlarda $\% 55,9$ oranlarında olduğu, buna karşılık genellikle ileri evrede tanı konulan kuyruk yerleşimli tümörler, erkeklerde daha sıktır ve bu oran istatistiksel olarak anlamlıdır $(\% 9,1$ vs. $\% 5,9 ; \quad p=0,049)$ (Tablo-2, Şekil-1).

Pankreas tümörlerin yaş grupları ve cinsiyet ile ilişkisi incelendiğinde; erkeklerde \%30,8 oranında 60-69 yaşta en yüksek sıklıkta, kadınlarda ise \% 34,1 oranı ile 70 yaş üzeri grupta gözlenmiştir. İkinci sırada 50-59 yaş grubunda erkeklerde $\% 27,8$, kadınlarda \%23,1 oranında saptanmıştır. Erkek ve kadın oranları arasındaki fark anlamlı bulunmuştur (Ki Kare: 19,233; p=0,004) (Tablo-3, Şekil-2). 


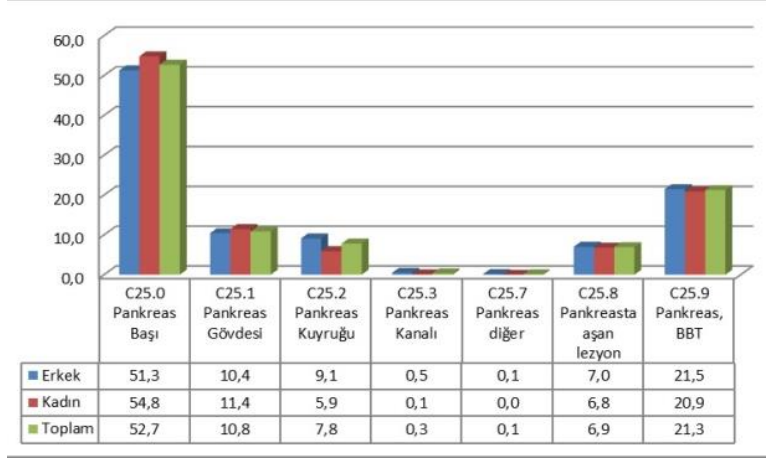

Şekil-1. ICD-O3'e sınıflamasına göre pankreas kanserlerinin yerleşim şekillerinin cinsiyet ile ilişkisinin sütun grafik ile karşılaştırmalı gösterilmesi

Ekzokrin tümörler, endokrin tümörlerden anlamlı oranda fazla izlenmektedir (\%95 vs. \%5; $\mathrm{p}=0.002$ ) (Tablo-4). Ekzokrin tümörlerin hemen tamamı adenokarsinom histolojisinde iken, nöroendokrin karsinom en sık karşılaşılan $(\% 94,7)$ endokrin tümör tipidir. Tüm yaş grupları içerisinde pankreas adenokarsinomları yaş arttıkça artmaktadır.

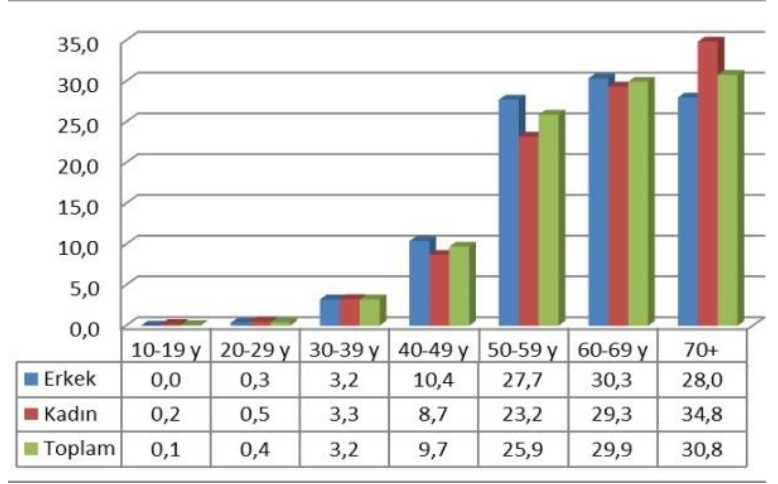

Şekil-2. Pankreas kanserlerinin cinsiyetlere göre yaş grupları arasında dağılımının sütun grafik kullanılarak gösterilmesi.

1992 yılından 2014 yılı sonuna kadar kaydedilen pankreas kanseri olgularında doğrusal bir artış mevcuttur ve yıllara göre olan bu artış anlamlıdır (Tablo-6, GLM: $\quad F=10,91, \quad p<0,001)$. Artış cinsiyetler arasında farklılık göstermektedir. Erkeklerde daha yüksek ve doğrusal artış mevcut iken; kadınlarda benzer şekilde bir artış izlenmemiştir (GLM: $F=4,988 ; p=0,026)$ (Şekil-3).

Tablo-3. Pankreas kanserlerinin cinsiyetlere göre yaş grupları arasında dağılımının gösterilmesi.

\begin{tabular}{|c|c|c|c|c|c|c|}
\hline \multirow{2}{*}{ Pankreas } & \multicolumn{2}{|l|}{ Erkek } & \multicolumn{2}{|l|}{ Kadın } & \multicolumn{2}{|c|}{ Toplam } \\
\hline & $\mathrm{n}$ & $\%$ & $\mathrm{n}$ & $\%$ & $\mathrm{n}$ & $\%$ \\
\hline $10-19 y$ & 0 & 0,0 & 2 & 0,2 & 2 & 0,1 \\
\hline $20-29 y$ & 5 & 0,3 & 5 & 0,5 & 10 & 0,4 \\
\hline $30-39 y$ & 48 & 3,2 & 33 & 3,3 & 81 & 3,2 \\
\hline $40-49 y$ & 155 & 10,4 & 88 & 8,7 & 243 & 9,7 \\
\hline $50-59$ y & 414 & 27,7 & 235 & 23,2 & 649 & 25,9 \\
\hline $60-69 y$ & 453 & 30,3 & 297 & 29,3 & 750 & 29,9 \\
\hline $70+$ & 418 & 28,0 & 353 & 34,8 & 771 & 30,8 \\
\hline Toplam & 1.493 & 100,0 & 1.013 & 100,0 & 2.506 & 100,0 \\
\hline
\end{tabular}

Ki Kare: 19,318; $p=, 004$

Tablo-4. Pankreas kanserlerinin köken aldıkları bez özelliklerine göre dağılımının gösterilmesi

\begin{tabular}{lllllll}
\hline & Erkek & \multicolumn{3}{c}{ Kadın } & \multicolumn{3}{c}{ Toplam } \\
Sekresyon Özellikleri & $\mathbf{n}$ & $\%^{*}$ & $\mathbf{n}$ & $\%^{*}$ & $\mathbf{n}$ & $\%^{*}$ \\
\hline Endokrin Pankreas & 49 & 4,0 & 60 & 6,3 & 109 & 4,5 \\
Ekzokrin Pankreas & 1.263 & 96,0 & 833 & 93,7 & 2.096 & 95,5 \\
Total & 1.444 & $60,2^{* *}$ & 954 & $39,8^{* *}$ & 2.398 & 100,0 \\
\hline
\end{tabular}

Fischer Exact $\mathrm{p}=0,002$

* Sütun yüzdesi; ** Satır Yüzdesi 


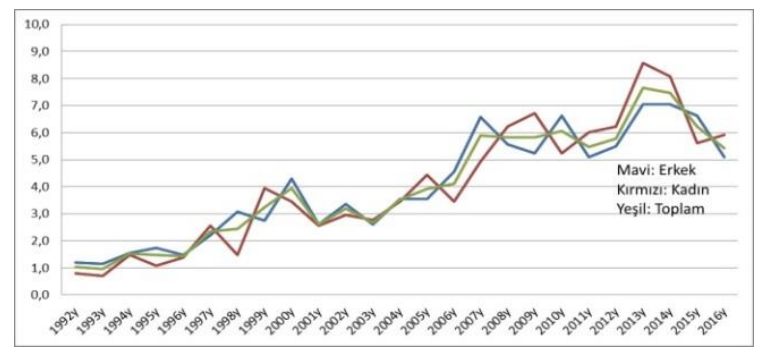

Şekil-3. Pankreas kanseri olgu sayılarının yıllara ve cinsiyete göre artışının çizgi grafik ile gösterilmesi.

Her iki cinsiyette benzer şekilde hastalık en sık uzak organ metastazı olduğu dönemde tanı almaktadır (Erkekler için \%54,2, kadınlar için $\% 36,8 ; p=0,113$ ) (Şekil-4).

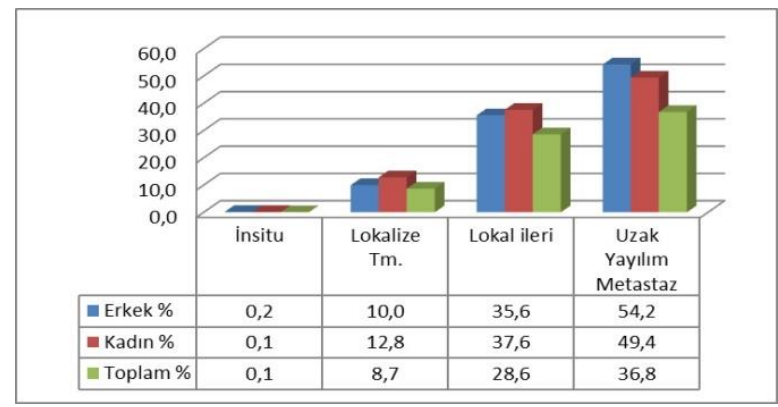

Şekil-4. Pankreas kanserlerinin evrelere göre dağılımının cinsiyetlerdeki değişiminin sütun grafik ile gösterilmesi

Ayrıca kuyruk yerleşimli tümörlere anlamlı oranda metastatik evrede tanı konulabilmektedir (\%76,2; $p<0,001$ ) (Şekil-5).

Hastalık prognozu oldukça kötü olup; 2-, 5- ve 10-yıllık GSK oranları sırasıyla \%15,9, \%8,3 ve \%6,0; ortanca GSK 7 aydır (Tablo-5). Yıllara göre artış tablo 6'da ayrıntılı olarak verilmiştir.

Kadınlarda GSK erkeklerden daha iyidir. Beş yıllık GSK erkeklerde \%11,3 iken; kadınlarda $\% 15,4$ olup anlamlı bulunmuştur $(p<0,001)$. Pankreas kanserinde evrelere sağkalım grafiği,
(Şekil-6)'da görülmektedir. En iyi prognoz, karsinoid tümör tanısına sahip olanlarda izlenmiştir (5-yıllık GSK \%60,0).

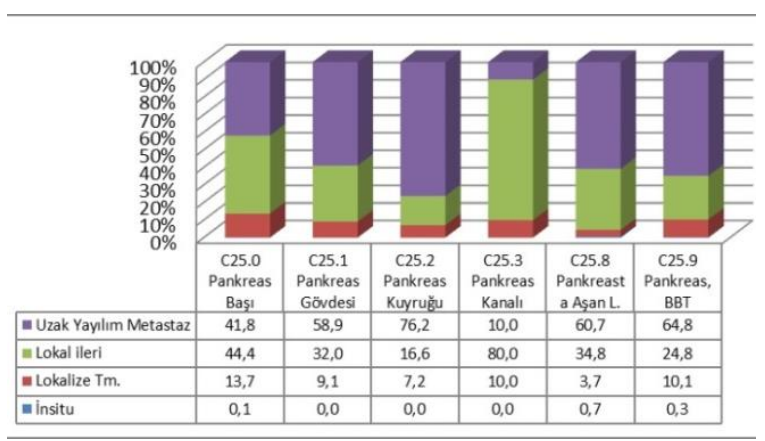

Şekil-5. Pankreas kanserlerinin yerleşim yerleri ile tanı aldıkları evre dağılımının sütun grafik ile gösterilmesi

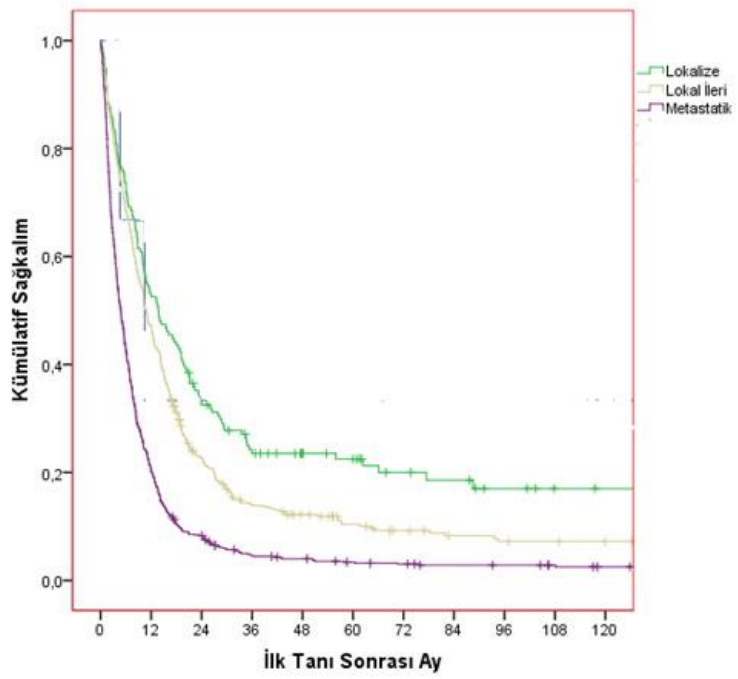

Şekil-6. Pankreas kanserlerinde genel sağkalım sürelerinin evrelere göre grafik ile gösterilmesi.

Tablo-5. Pankreas kanserlerinin cinsiyetlere göre genel sağkalım sürelerinin gösterilmesi.

\begin{tabular}{|c|c|c|c|c|c|c|c|c|c|}
\hline Cinsiyet & $\mathbf{n}$ & $\begin{array}{l}\text { Ölüm } \\
\text { n }\end{array}$ & $\begin{array}{l}\text { Sağ } \\
\%\end{array}$ & $\begin{array}{l}12 \text { ay } \\
\text { (1 Y Il) }\end{array}$ & $\begin{array}{l}24 \text { ay } \\
\text { (2 Y II) }\end{array}$ & $\begin{array}{l}36 \text { ay } \\
\text { (3 Y II) }\end{array}$ & $\begin{array}{l}60 \text { ay } \\
\text { (5 yıl) }\end{array}$ & $\begin{array}{l}96 \text { ay } \\
\text { (8 Y II) }\end{array}$ & $\begin{array}{l}120 \text { ay } \\
(10 \text { Yıl) }\end{array}$ \\
\hline Erkek & 1.027 & 971 & 5,5 & 29,9 & 13,3 & 8,4 & 6,3 & 4,5 & 3,7 \\
\hline Kadın & 725 & 649 & 10,5 & 37,2 & 19,4 & 13,4 & 11,2 & 10,4 & 9,4 \\
\hline
\end{tabular}

Wilcoxon (Gehan) Statistic $=10,899 \mathrm{p}<0,0002$ 
Tablo-6. Pankreas kanseri olgu sayılarının yıllara ve cinsiyete göre artışının tablo gösterilmesi.

\begin{tabular}{|c|c|c|c|c|c|c|}
\hline $\begin{array}{l}\text { Pankreas } \\
\text { Tm. }\end{array}$ & Erkek & & Kadın & & Toplan & \\
\hline Yıllar & $\mathbf{n}$ & $\%$ & $\mathrm{n}$ & $\%$ & $\mathbf{n}$ & $\%$ \\
\hline 1992 & 18 & 1,2 & 8 & 0,79 & 26 & 1,0 \\
\hline 1993 & 17 & 1,1 & 7 & 0,69 & 24 & 1,0 \\
\hline 1994 & 23 & 1,5 & 15 & 1,48 & 38 & 1,5 \\
\hline 1995 & 26 & 1,7 & 11 & 1,08 & 37 & 1,5 \\
\hline 1996 & 22 & 1,5 & 14 & 1,38 & 36 & 1,4 \\
\hline 1997 & 33 & 2,2 & 26 & 2,56 & 59 & 2,4 \\
\hline 1998 & 46 & 3,1 & 15 & 1,48 & 61 & 2,4 \\
\hline 1999 & 41 & 2,7 & 40 & 3,94 & 81 & 3,2 \\
\hline 2000 & 64 & 4,3 & 35 & 3,45 & 99 & 3,9 \\
\hline 2001 & 39 & 2,6 & 26 & 2,56 & 65 & 2,6 \\
\hline 2002 & 50 & 3,3 & 30 & 2,96 & 80 & 3,2 \\
\hline 2003 & 39 & 2,6 & 28 & 2,76 & 67 & 2,7 \\
\hline 2004 & 53 & 3,5 & 35 & 3,45 & 88 & 3,5 \\
\hline 2005 & 53 & 3,5 & 45 & 4,44 & 98 & 3,9 \\
\hline 2006 & 68 & 4,6 & 35 & 3,45 & 103 & 4,1 \\
\hline 2007 & 98 & 6,6 & 50 & 4,93 & 148 & 5,9 \\
\hline 2008 & 83 & 5,6 & 63 & 6,21 & 146 & 5,8 \\
\hline 2009 & 78 & 5,2 & 68 & 6,71 & 146 & 5,8 \\
\hline 2010 & 99 & 6,6 & 53 & 5,23 & 152 & 6,1 \\
\hline 2011 & 76 & 5,1 & 61 & 6,02 & 137 & 5,5 \\
\hline 2012 & 82 & 5,5 & 63 & 6,21 & 145 & 5,8 \\
\hline 2013 & 105 & 7,0 & 87 & 8,58 & 192 & 7,7 \\
\hline 2014 & 105 & 7,0 & 82 & 8,09 & 187 & 7,5 \\
\hline 2015 & 99 & 6,6 & 57 & 5,62 & 156 & 6,2 \\
\hline 2016 & 76 & 5,1 & 60 & 5,92 & 136 & 5,4 \\
\hline Toplam & 1.493 & 100,0 & 1.014 & 100,00 & 2.507 & 100,0 \\
\hline
\end{tabular}

\section{Tartışma}

GLOBOCAN 2018 verilerine göre total kanser vakalarında birinci sırada \%11,6 ile solunum sistemi kanserleri yer almaktadır (1). Bu kanser tüm kanser ölümlerinin \%18,4'ünü oluşturur. Türkiye kanser istatistiklerinde erkeklerde yaşa göre standardize edilmiş hızlar (Türkiye Birleşik Veri Tabanı, 2009- 2013) 100.000 kişide 67,6 ile solunum sistemi birinci sırada, 55,6 ile Gis kanserleri ikinci sıradadır. EÜKAM tarafından 1992-2017 yılları arasında 25 yıllık dönemde EÜH'de 117.139 kanser kaydı gerçekleştirilmiş olup; bunun 19.542 (\%16,5)'si gastrointestinal sistem kanseridir. Gastrointestinal sistem kanserlerinin 2.507 (\%12,8)'si pankreasa lokalize kanserlerdir. GLOBOCAN 2018 tahminlerine göre, 2018 yılında 458.918 yeni olgu sayısı ve 432.242 ölüm ile (tüm kanser nedenli ölümlerin $\left.\% 4,5^{\prime} i\right)$ on birinci en sık karşılaşılan kanser tipi olarak verilmektedir (1). Amerika Birleşik Devletleri'nde kanser ilişkili ölümlerinin en sık dördüncü nedeni pankreas kanseridir.

Olgularımızın 1.493'ü (\%59,5) erkek, 1.014'ü $(\% 40,5)$ kadın olup; istatistiksel olarak anlamlı olmamakla beraber erkek olgularımız kadın olgularımızdan daha fazladır. Daha önce yapılan 
çalışmalarda da serimizle benzer şekilde pankreas kanser sıklığının erkeklerde daha fazla olduğu gösterilmiştir (4). Bu durum biyolojik ve cinsiyete bağlı davranışlarla ilişkilendirilmiştir. Erkeklerde pankreas kanser riskini artıran davranışlar özellikle sigara ve alkol kullanımı, viseral yağlanma kadınlara göre daha fazladır ve buna bağlı olarak erkeklerde daha sık karşılaşıldığı düşünülmektedir (4). Bosetti $C$ ve ark.'larının sonuçlarında da bizimkilerle benzer olarak cinsiyetler arası anlamlı fark olmamakla beraber erkek olgu sayısının fazla olduğu, ek olarak özellikle 2007 yılından sonra erkek olgu sayılarında azalma izlendiği belirtilmiştir (5). Buna karşın bizim serimize bakıldığında, kadın olgu sayısında yıllarla belirgin bir artış izlenmezken; erkek olgu sayısında istatistiksel anlamlı oranda doğrusal bir artış saptanmıştır. Ülkemizdeki farkındalığın, tanı ve tedavi olanaklarının artması olgu sayımızdaki artışı açıklayabilir ancak cinsiyetler arasındaki fark aynı şekilde biyolojik ve davranışsal farklıııkla yorumlanabilir.

Çalışmamızda yaş grupları açısından dağııım incelendiğinde, özellikle 40 yaş altında her iki cinsiyette olgu sayımızın çok az olduğu görülmektedir. Buna karşın erkeklerde 60 yaş, kadınlarda ise 70 yaş üzerinde görülme sıklığında artış mevcuttur. Bizim serimizle benzer olarak, literatürde de 40 yaş altında pankreas kanseri insidansı düşük olup özellikle 50 yaştan sonra insidansta artış belirtilmektedir $(6,7)$.

Çalışmamızda ekzokrin tümörler, anlamlı oranda fazla izlenirken, bunların hemen tamamı adenokarsinom histolojisindedir. Minicozzi $P$ ve ark.'Iarının Avrupa'daki pankreas ve safra yolları kanserlerinin insidans, mortalite ve dağılımlarını değerlendirdikleri çalışmada da en sık ekzokrin tümörler ve histopatoloji olarak da adenokarsinom ile karşılaşıldığı belirtilmiştir (8). Endokrin tümörlerin yaygınlığı ve en sık izlenen histolojik tip, hem kayıt şekillerinde hem de tanı şekillerindeki farklılıklar nedeni ile toplumlar arasında farklı oranlarda rapor edilmiştir.

Pankreas kanserinde sağkalım oranları tüm dünyada oldukça düşüktür. Bizim olgularımızdaki sonuçlara bakıldığında, prognoz oldukça kötü olup; 2-, 5- ve 10-yıllık GSK oranları sırasıyla $\% 15,9, \% 8,3$ ve $\% 6,0$; ortanca GSK 7 aydır. Hastalarımızın çok az bir kısmı 2 yıl yaşayabilmektedir. Literatürde de benzer sağkalım oranları mevcuttur. Özellikle tanı yaşı ve tanı evresi arttıkça hastaların çok az bir kısmının 6 aylık ortalama sağkalıma ulaştıkları izlenmektedir (7). Pankreas kanserine bağlı en yüksek mortalite oranları Baltık ülkeleri ve bazı Doğu/Kuzey Avrupa ülkelerinde raporlanmıştır (5). Bu oran yaklaşık olarak 9/100.000 olarak verilmiştir. Sun $\mathrm{H}$ ve ark.'larının yıllar içerisinde pankreas kanseri sağkalımında iyileşmeyi vurguladıkları çalışmalarında 1- ve 5-yıllık sağkalım oranları en yüksek olan dönemde bile sırasıyla \%28,2 ve \%6,9 olarak raporlanmıştır (7).

\section{Sonuç}

Ege Üniversitesi Hastanesinde EÜKAM tarafından 1992-2017 arasında, 117.139 kanser kaydı gerçekleştirilmiş olup bunların 2.507'si pankreas kanseridir. Pankreas kanserinde yıllara göre doğrusal artış vardır ve genellikle uzak metastatik evrede tanı konulmaktadır. En sık görülme yaş grubu olan 60-69 yaş grubu için 5yıllık GSK \% 1,4 olarak bulunmuştur. Kadınlarda GSK erkeklere göre daha iyidir.

Teşekkür: 25 yıllık süre içinde hasta alımında emekleri geçen Genel Cerrahi AD öğretim üyeleri Prof. Dr. Ali Menteş, Prof. Dr. Yıldıray Yüzer, Prof. Dr. Yaman Tokat, Prof. Dr. Ahmet Çoker, Prof. Dr. Murat Sözbilen, Doç Dr. Murat Kılıç, istatistik analizleri yapan EüKAM bilgisayar ve istatistik uzmanı Ömer Karaca'ya, EÜKAM kanser kayıt elemanlarına teşekkürü borç biliriz.

Çıkar çatışması: Yazarlar çıkar çatışması beyan etmemişlerdir.

\section{Kaynaklar}

1. Bray, F, Ferlay J, Soerjomataram I, Siegel RL., Torre LA and Jemal A. Global cancer statistics 2018: GLOBOCAN estimates of incidence and mortality worldwide for 36 cancers in 185 countries. CA: A Cancer Journal for Clinicians 2018;68(6):394-424.

2. Haydaroglu A, Sert F, Caner A. Epidemiological and overall survival characteristics of cancer patients in Ege University Hospital database. Ege Tıp Dergisi / Ege Journal of Medicine 2019; 58: Ek Sayı /Suppl 1-9.

3. Rawla P, Sunkara T, Gaduputi V. Epidemiology of Pancreatic Cancer: Global Trends, Etiology and Risk Factors. World J Oncol 2019 Feb;10(1):10-27. doi: 10.14740/wjon1166. 
4. Maisonneuve $P$, Lowenfels $A B$. Risk factors for pancreatic cancer: a summary review of meta-analytical studies. Int J Epidemiol 2015;44(1):186-98.

5. Bosetti C, Bertuccio P, Negri E, La Vecchia C, Zeegers MP, Boffetta P. Pancreatic cancer: overview of descriptive epidemiology. Mol Carcinog 2012 Jan;51(1):3-13. doi: 10.1002/mc.20785.

6. Brune KA, Lau B, Palmisano E, et al. Importance of age of onset in pancreatic cancer kindreds. J Natl Cancer Inst 2010;102(2):119-26.

7. Sun $\mathrm{H}, \mathrm{Ma} \mathrm{H}$, Hong G, Sun $\mathrm{H}$, Wang J. Survival improvement in patients with pancreatic cancer by decade: a period analysis of the SEER database, 1981-2010. Sci Rep 2014 Oct 23;4:6747. doi: 10.1038/srep06747.

8. Minicozzi P, Cassetti T, Vener C, Sant M. Analysis of incidence, mortality and survival for pancreatic and biliary tract cancers across Europe, with assessment of influence of revised European age standardisation on estimates. Cancer Epidemiol. 2018 Aug;55:52-60. doi: 10.1016/j.canep.2018.04.011. 